\title{
The Function of Physical Education for Building Social Values
}

\author{
Jing YUAN \\ College of Physical Education and Sport \\ Henan Agricultural University, \\ Zhengzhou 450002, China
}

\begin{abstract}
Two kinds of values are generally distinguished in sociology and philosophy: objective ones and subjective ones. Objective values are those objectively existing objects of reality (nature or society) which individuals, social groups, classes or society as a whole normally assess as either positive or negative. These two concepts are expressed in the following alternatives: beneficial/harmful, useful/useless, progressive/reactionary, moral/immoral, productive/unproductive, and so on. Among the objective values are natural phenomena, such as sources of natural wealth or disasters, man-made articles belonging to his material culture, the use value of goods, people's actions, works of art and literature, scientific works, physical education as part of man's general culture, and similar phenomena.
\end{abstract}

Keywords-function, physical education, social values, positive, negative

\section{INTRODUCTION}

As a social being, man sometimes decides that values are either positive or negative on the basis of accidental circumstances and sometimes he is quite indifferent to them. At a given level of social development, society strives to define certain common norms and criteria to be applied when assessing objective values. These general norms and criteria are in fact subjective values. An evaluation of the objects and phenomena surrounding us would seem pointless, as would a descriptive didactic evaluation, unless identical objective values were evaluated in diametrically opposed terms at one and the same time. The differences in evaluation cannot be explained merely on the basis of the age and professional milieu of the person passing judgment. His philosophical, ideological and political make-up must also be taken into consideration. In an antagonistic class society, the criteria for assessing objective values, worked out by representatives of the governing class, are usually presented as inter-subjective, universally human values.

\section{OBJective VALUe Resulting FROM Human ACTIVITY}

Considered in general terms, every objective value resulting from human activity is normally judged by society as a positive phenomenon, insofar as it generally fulfills an important function in satisfying the needs of society as a whole. Positive and negative values are only applied to concrete examples or activities and their individual results. Indeed, subjective values change fundamentally from one historical period to another. Thus, while athletic games were judged positively in primitive society and antiquity, in the age of feudalism under the influence of church teaching national athletic games were no longer rated highly by the majority of the people, although the knightly system of military and physical education was valued quite highly.

Since physical education and sport are primarily activities which do not alienate themselves directly as specific material values, an aspect that lies outside the scope of this paper, we shall here examine the objective social values from the point of view of the social activity from which they originate. Furthermore, we shall try to point out the features common to both sport and other activities in order to define their specific characteristics. In conclusion we shall consider the reasons for the great popularity of physical education and sport and their prospects in the light of the present technological revolution.

\section{Physical Education AND Sport as Social VAlues}

Seen in general terms, physical education and sport are social values which form an important component of human culture. However, there have been periods in history in which certain types of athletic activity were regarded negatively by the governing classes (an example is the abolition of the Olympic Games in 394 A. D. by Emperor Theodosius I). [1]On other occasions society has overrated athletic activities to the detriment of other forms of activity (a situation which occurred in ancient Sparta).

Sport is closely connected with other activities providing social values. Archaeologists, ethnographers and sports historians testify to the fact that animal sculptures and figures bearing the marks of arrows, harpoons and spears existed already in the Palaeolithic period. Furthermore, primitive societies observe the custom of attacking various animal images drawn on sand with hunting implements, shooting at stuffed animals etc., before setting off for the hunt. It is interesting to note that the position of the heart, the organ vital for killing the animal, was schematically indicated on the figures. An analysis and judicious interpretation of these figures (as well as a number of other factors) allows one to conclude that athletic exercises originated from work and represented training which increased the hunter's efficiency.

An analysis and judicious interpretation of the above example and of other archaeological data also enables us to conclude that athletic activity was originally not only connected with work but also with other activities, e. g. 
aesthetic, magical-ritual, semeiotic or scientific, which were ultimately determined by work, the needs of production and primitive man's struggle for existence as a result of his extremely difficult living conditions.

The use of physical training in perfecting a labor process shows that late Paleolithic man practiced sports, physical training and physical education. Since the animal images represented a somewhat stylized reproduction of existing beings and bore the mark of their creator's individuality, we are also confronted with an aesthetic activity, the earliest form of art. The belief that striking the animal before the hunt would make it easier to kill it during the hunt convinces us of the existence of a magical, religious activity. The identification of the image with the real object during magical rites and at the same time the awareness of the fictitiousness of this identification in work is proof of the presence of complex semeiotic and mental activities. The faithfulness of the animal likeness, the indication of the position of its heart and the knowledge that this was the animal's most vital organ shows that Paleolithic man was capable of research, which later developed into science. It has been possible to demonstrate that the above activities came into being and developed because they made work more efficient.

\section{EACH ACTIVITY REPRESENTS A COMPLEX DYNAMIC SYSTEM}

However, common origins are not the only link between sport and other forms of activity. We can note the following in the light of contemporary systematic and structural research methods: each activity represents a complex dynamic system. Activities differ in their content and in the forms of interaction of their components, but they have identical structures.[2] The common factor linking the social values of activities which have different concrete contents, is their structure. Their common feature consists in the fact that each activity presupposes an acting subject, an object towards which the activity is directed, and a result.

All value-related social activities and their positive results meet certain needs of society and represent integral components of the general culture of a nation, or of mankind as a whole. All value-related social activities influence and, as a rule, benefit each other. The very fact that physical education has a favorable effect on man's health (providing that the necessary norms and rules are observed) means that it is one of the most important ways of increasing the efficiency of other activities. Sport, like all other activities, requires a considerable amount of preparatory work and a mastery of certain fields of man's social experience in order to obtain significant concrete results, which are positively assessed by society. [3] The preparation needed to set a record in a given sport requires concentrated training not only in the given discipline but in others as well. Therefore, a long period of systematic work is needed for the successful accomplishment of some activities. As a rule, the person with the best teacher obtains the best results (all other conditions being equal).

In all activities, will, interest and ability are the most important requirements for obtaining an improved result. Any activity requires that a person observes certain "don'ts", if not "do's". In many activities, including sport, these "do's" and "don'ts" are so well-defined that the activities can be classified as semeiotic systems in which objects are considered as either autonomously or non-autonomously used signs, and complex objects are composed of elementary signs in accordance with the rules of the system (e. g. music and ballet in art, certain systems of logic in mathematics, and chess and other games in sports).[4]

\section{The Prestige of Activities INCLUding SPORT}

Every activity is linked with prestige. In the semeiotic process every result newly obtained in the course of an activity acts as a sign, as a symbol of the assertion of the personality. Every activity also has an aesthetic element (cf. "a nicely proven theory" or "a beautiful game"). It is well known that a feeling of aesthetic pleasure is evoked not only by objects created by man (e.g. works of art) but also by objects of nature (e. g. animals, plants, mountains, rocks, etc.).[5] Nature's most perfect product - man, his beauty, body, physical qualities towards whose perfection sport greatly contributes, is an object of aesthetic pleasure to an even greater extent. Physical exercises touch on art directly when, by forming a certain system, they represent signs, means of communication or means of expressing emotion and other general values, i. e. when they become semeiotic systems possessing both syntax and semantics. The recent popularity of sports such as artistic gymnastics and figure skating is no coincidence.

One of the most outstanding features of man's mind is possibly the fact that the immediate and ultimate aims (i.e., motives) are not only different but often also contradictory. When preparing for a competition, an athlete experiences a host of negative feelings. Nevertheless he stubbornly continues his training with the ultimate aim, the motive, in mind. Furthermore, the athlete has to subordinate his personal interests and feelings to those of the team and weigh the immediate aim against the motive (take the example of a footballer who can shoot a goal but instead passes the ball to another player who has a better chance to score).

\section{THE DIFFERENCES BETWEEN SPORT AND WORK}

The differences between sport and other activities cannot be demonstrated in this paper, so we shall limit ourselves to considering some of the differences between sport and work. As a rule, any natural product, or product created during social activity, can be the object of work. This means that the objects towards which man's efforts are directed are outside the subject of work. The object of physical exercise is man himself, his motor and muscular strength, his ability to react, his internal organs and the state of his entire organism. As is known, by changing the objects around him, man changes his nature and with it his physical qualities during the process of material labor.

However, man's motor and muscular system changes indirectly as a result of work, i. e. by changing the object of labor. On the other hand, physical exercise, which directly changes man's organism, leads indirectly to a general increase in productivity. Results are obtained in work by employing artificial tools which form a sort of link between the individual 
and the world around him and by means of which he changes his surroundings. Perfecting tools is one of the most important prerequisites for progress in work and in production as a whole. In sport, however, tasks are carried out without the intermediary of tools. The equipment used in sport is not a tool but merely the means of artificially creating complex situations analogous to those which can be encountered in real life and which require a vast effort and the maximum development of strength, skill and speed.

Even attributes such as hockey sticks and tennis rackets are not tools. Like working tools they provide man's hands with new potentials, but unlike working tools they do not help to change material objects. With these tools and with his energy, skills and experience, man exerts influence on an object and changes it either qualitatively or quantitatively to such an extent that we are often obliged to speak of the creation of a previously unknown object and to give it a new name. In sport, on the other hand, man only improves his physical (and other) qualities. The difference between work and sport is highly significant as regards their ultimate results. The results obtained from work are always objects extraneous to man and the product created by man is alienated from its creator by the conditions of production.

Moreover, as Marx has shown, under capitalist conditions this alienation leads to the identification of the object's social functions with its natural functions and to an objectification of social relations ("commodity fetishism"). [6]The results of sport on the other hand, which are not directly alienated from the subject but constantly remain with him, are his own personal property. A record set by an athlete under given historical, spatial and temporal conditions is always his own property in the sense that he can make it public property whenever he wants. In this respect the prestige of a record is similar to that of a scientific discovery or invention or to the prestige of a work of art.

\section{CONCLUSION}

Work differs in that the rules for producing a new object are normally immediately put into practice (technical and other conditions permitting) and thus become popularized comparatively quickly. The results obtained by a person through constant athletic activity remain with him for the rest of his life and are constantly at his disposal. They can be neither bought nor sold (at least not in the sense in which manufactured goods are sold). Because of the "inalienability" of the results of athletic activity from the subject, complicated conflicts occur in an athlete's life when his achievements become a commercial object. When an artist sells a painting he sells the painting and not himself as a physical being, thus remaining free and independent of the commercial action. The athlete who sells his achievements to some extent also sells himself, since his achievements are an intrinsic part of himself as a physical being. Hence in a capitalist society tragic conflicts frequently occur in an athlete's life.

\section{REFERENCES}

[1] Australian Sports Commission and the Office of the Status of Women (1985) Women, Sport and the Media, Report to the Federal Government from the Working Group on Women in Sport. Canberra: AGPS.

[2] Baade, R. A., and Matheson, R. A. (2002) Bidding for the Olympics: fool's gold? In C. P. Barros, M. Ibrahimo and S. Szymanski (eds) Transatlantic Sport: the Comparative Economics of North American and European Sports. Cheltenham, UK: Edward Elgar, pp 127-151.

[3] Bacon, W. (1993)Watchdog's bark muffled. Reportage: Newsletter of the Australian Centre for Independent Journalism (UTS, Sydney), September: 3-5.

[4] Baka, R. (1976) Canadian federal government policy and the 1976 summer Olympics. Canadian Association for Health, Physical Education and Recreation Journal, 42(1): 52-60.

[5] Baker, N. (1994a) The Games that almost weren't: London 1948. In Barney and Meier, op. cit., pp. 107-116.

[6] Baker, N. (1994b) Olympics or Tests: the disposition of the British sporting public, 1948. Sporting Traditions, 11(1): 57-74. 